\title{
Case report-immune recovery posterior scleritis in a HIV positive patient
}

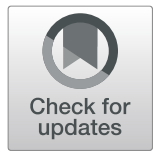

\author{
Xin Che ${ }^{\dagger}$, Jing Jiang ${ }^{\dagger}$, Yiwen Qian, Qingjian Li, Yu Zhang and Zhiliang Wang ${ }^{*}$ (D)
}

\begin{abstract}
Background: Posterior scleritis is an uncommon vision-threatening disorder that is often recurrent and difficult to cure due to its complex etiology. In HIV patients, posterior scleritis may develop several months after significant rise in CD4+ T-lymphocyte, even after several years, which may be diagnosed as late-onset immune recovery scleritis.

Case presentation: Here we report a case of posterior scleritis in a HIV positive patient who presented with severe periocular pain and decreased vision in the left eye, with exudative retinal detachment and optic nerve involvement.

Conclusions: Early differential diagnosis of immune recovery posterior scleritis and intensive corticosteroids treatment, can prevent vision loss effectively in HIV patients.
\end{abstract}

Keywords: HIV, Immune recovery posterior scleritis, HAART, Treatment, Case report

\section{Background}

Posterior scleritis refers to a heterogeneous group of disorders characterized by chronic inflammatory response, which is associated with exudative retinal detachment and optic nerve involvement. It is commonly confounded with ocular tumors and other inflammatory ocular disorders, like choroidal tumor and Vogt-Koyanagi-Harada syndrome [1]. A part of scleritis is due to infections [2-4], about $10 \%$ scleritis is associated with systemic disorders like rheumatic diseases and most of the origin is idiopathic $[5,6]$.

Immune recovery scleritis, is a noninfectious scleral inflammation which develops in patients with CMV retinitis or other intraocular infections after substantial increase in CD4+ T-lymphocyte. Immune recovery scleritis in human immunodeficiency virus (HIV) patients is uncommon, which may develop several months after the highly active anti-retroviral therapy (HAART) initiation when the immune function is recovered [7].

\footnotetext{
* Correspondence: ophwzl@163.com

${ }^{\dagger}$ Xin Che and Jing Jiang contributed equally to this work.

Department of Ophthalmology, Huashan Hospital of Fudan University, No.

12, Middle Urumqi Road, Shanghai 200040, China
}

Early diagnosis and intervention in treating immune recovery scleritis is necessary to avoid vision loss. Therapeutic strategies focus on sub-conjunctival triamcinolone injections for anterior scleritis, and systemic corticosteroids with or without systemic immunosuppressive drugs for severe scleritis [8]. But so far, treatment strategies for HIV patients with posterior scleritis remain controversial.

In this case, we report a HIV patient who was diagnosed with presumed immune recovery posterior scleritis unassociated with infectious etiology or rheumatologic diseases.

\section{Case presentation}

A 37-year-old woman came to our eye clinic with complaints history of ocular and periocular pain in the left eye, irradiating to the ipsilateral forehead, and decreased vision with a central scotoma. Her best-corrected visual acuity (BCVA) was 20/20 (OD) and 20/67 (OS), with intraocular pressure (IOP) of $11 \mathrm{mmHg}(\mathrm{OD})$ and $8 \mathrm{mmHg}$ (OS). Examination of the right eye was normal. Anterior segment examination of the left eye revealed severe chemosis, subconjunctival hemorrhage (Fig. 1a). Fundus examination showed the disc edema and retinochoroidal folds (Fig.1b). B-ultrasound (Fig.1c) and optical coherence

(c) The Author(s). 2020 Open Access This article is licensed under a Creative Commons Attribution 4.0 International License, which permits use, sharing, adaptation, distribution and reproduction in any medium or format, as long as you give appropriate credit to the original author(s) and the source, provide a link to the Creative Commons licence, and indicate if changes were made. The images or other third party material in this article are included in the article's Creative Commons licence, unless indicated otherwise in a credit line to the material. If material is not included in the article's Creative Commons licence and your intended use is not permitted by statutory regulation or exceeds the permitted use, you will need to obtain permission directly from the copyright holder. To view a copy of this licence, visit http://creativecommons.org/licenses/by/4.0/ The Creative Commons Public Domain Dedication waiver (http://creativecommons.org/publicdomain/zero/1.0/) applies to the data made available in this article, unless otherwise stated in a credit line to the data. 

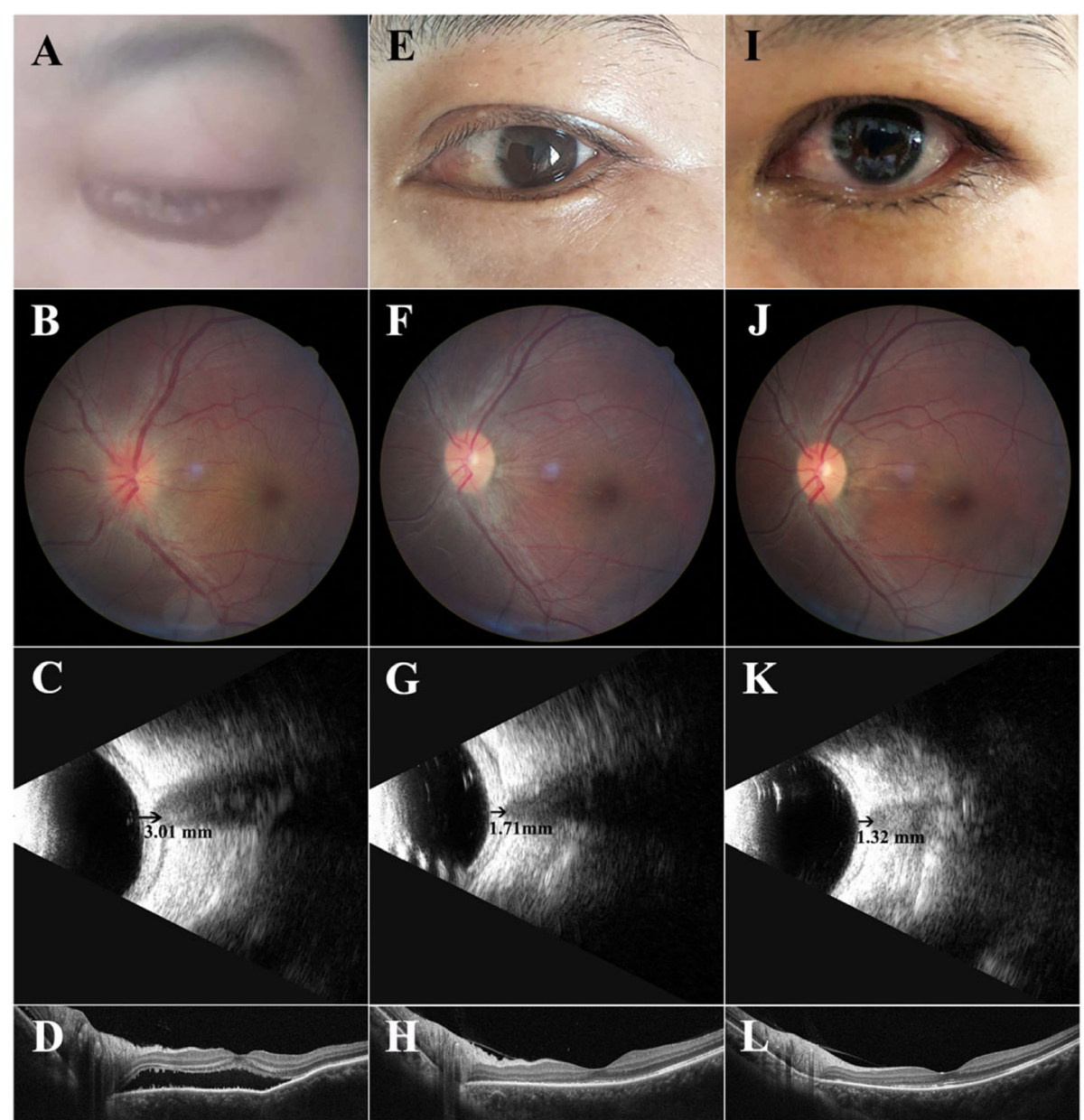

Fig. 1 Anterior segment photography of the left eye. a. Severe chemosis, subconjunctival hemorrhage at the first visit. e. Regression of chemosis and complete resolution of conjunctival redness 1 month later. i. No obvious abnormality 6 month later. Fundus photograph of the left eye. $\mathbf{b}$. Presence of optic nerve swelling and chorioretinal folds at the first visit. f. Partial regression of optic nerve swelling and progressive resolution of chorioretinal folds 1 month later. j. Absolute regression of optic nerve swelling and chorioretinal folds 6 month later. B-ultrasound of the left eye. c. Retrobulbar edema with the typical "T" sign at the first visit. g. Reduction of retrobulbar edema 1 month later. k. Mild retrobulbar edema 6 month later. OCT of the left eye. $\mathbf{d}$. Exudative retinal detachment at the first visit. $\mathbf{h}$. Regression of retinal detachment 1 month later. I. Normal retinal structure 6 month later.

tomography (OCT) (Fig. 1d) revealed retrobulbar edema with typical " $T$ " sign and exudative retinal detachment, suggesting posterior scleritis. She was systemically asymptomatic, with a normal hematology index, negative rheumatoid factors, complement fractions $\mathrm{C} 3$ and $\mathrm{C} 4$, ANA, ANCA, circulating immunocomplexes and a normal orbital magnetic resonance imaging (MRI). Serologic tests for syphilis, tuberculosis, hepatitis $\mathrm{B}$ and $\mathrm{C}$ were negative.

She was under consistent HAART for 3 years, during which her CD4 counts significantly peaked from 103 cells $/ \mu \mathrm{L}$ to 432 cells $/ \mu \mathrm{L}$. When she presented to our hospital with severe posterior scleritis, the CD4 count has further elevated to 698 cells/ $\mu \mathrm{L}$ (normal range 400-1300 cells $/ \mu \mathrm{L}$ ) and the HIV viral load was tested below the detection level.
The patient was subconjunctivally injected with Triamcinolone $(1 \mathrm{mg})$ at our outpatient service immediately, but showed no signs of improvement. One week later, she underwent a diagnostic pars plana vitrectomy to rule out infectious etiology, with an intravitreal injection of $4 \mathrm{mg}$ Triamcinolone. Molecular analysis of vitreous aspirate detected low titer of Aspergillus sydowii DNA, but was neglected as the patient did not show symptoms of endophthalmitis, which was presumed as a non-viable infection. After vitrectomy, topical $0.1 \%$ Dexamethasone eyedrops four times daily and ointment every night was prescribed. Surprisingly, within 5 days her vision improved.

During her 1 month follow-up, the left eye showed a visual acuity of $20 / 20$, chemosis and subconjunctival hemorrhage was completely resolved (Fig.1e), the optic 
disc was normal while retinochoroidal folds still existed (Fig.1f). Ultrasound (Fig.1g) and OCT (Fig. 1h) showed a reduction of retrobulbar edema and complete regression of retinal detachment. Since the patient showed an excellent therapeutic response, the topical $0.1 \%$ Dexamethasone eyedrops and ointment was continued for 6 months. Then the follow-up BCVA was 20/20, the retrobulbar inflammation subsided (Fig.1i, j, l), B-ultrasound showed mild edema (Fig. 1k).

\section{Discussion and conclusions}

Immune reconstitution inflammatory syndrome (IRIS) is commonly observed in HAART initiated HIV patients wherein the preexisting infection and inflammation worsens due to immune recovery. A variety of opportunistic pathogens including viruses, fungi and bacteria are associated with the development of IRIS [9]. Among various IRIS, immune recovery uveitis (IRU) is the common condition observed in HIV patients, while posterior scleritis rarely occur in HIV patients [10]. Literature survey showed only one case report on immune recovery scleritis in HIV patient [11].

To the best of our knowledge, this is the second case report presenting immune recovery scleritis in HIV patient. Although the vitreous biopsy was tested Aspergillus positive in our case, the infectious etiology was ruled out as symptoms of vasculitis and vitritis were absent and the patient responded well to topical corticosteroid treatment. Immune recovery was observed to be the only risk factor associated with posterior scleritis as the CD4 cells increased after HAART. However, for this patient, idiopathic scleritis could not be excluded.

IRIS is divided into early-onset $(<3$ months from HAART initiation) and late-onset presentation ( $>3$ months after HAART initiation). Early-onset IRIS is best explained by an increased immune response to either subclinical or partially treated opportunistic infections, late-onset is characterized by an immune reaction induced against non-viable pathogens, which has been reported even years after onset of HAART administration $[12,13]$. Our case is a presumed example of late-onset immune recovery posterior scleritis which has developed after 3 years of HAART.

During the early stage of infection, the vitreous inflammation may not be obvious. Considering our case is a HIV patient, diagnostic vitrectomy is important to do the PCR analysis to rule out infectious origin. Meanwhile, for the posterior scleritis, vitrectomy could eliminate inflammatory mediators in the eye, avoid cystoid macular edema, and could reduce the need for systemic long-term steroid, especially for the patients whose general situation may exacerbate after receiving systemic corticosteroids.
With the development of HAART globally, clinicians may encounter increasing numbers of individuals with IRIS. The ophthalmologist should be alert in considering IRIS as potential risk factor of posterior scleritis even several years after the initiation of HAART.

\section{Abbreviations}

HIV: Human immunodeficiency virus; HAART: Highly active anti-retroviral therapy; BCVA: Best-corrected visual acuity; OCT: Optical coherence tomography; MRI: Magnetic resonance imaging; IRIS: Immune reconstitution inflammatory syndrome; IRU: Immune recovery uveitis

\section{Acknowledgements \\ Not applicable.}

Authors' contributions

Design of the study (ZLW, YZ); data collection (XC, JJ, YWQ, QJL); preparation of the manuscript $(X C, J J, Z L W)$. All authors have read and approved the manuscript to be published

\section{Funding}

This study was supported by the National Natural Science Foundation of China NSFC, No. 81670868. The funders had no role in study design, data collection and analysis, decision on publish, or preparation of the manuscript.

\section{Availability of data and materials} Not applicable.

\section{Ethics approval and consent to participate}

The treatment for the patient is performed under the tenets of the Declaration of Helsinki. The patient reported in the study provided written informed consent for the surgery.

\section{Consent for publication}

The patient enrolled in the study have signed the written informed consent for the publication of their clinical details along with the images.

\section{Competing interests}

The authors declare no competing financial interests.

Received: 5 February 2020 Accepted: 22 June 2020

Published online: 02 July 2020

\section{References}

1. Alsharif HM, Al-Dahmash SA. Atypical posterior scleritis mimicking choroidal melanoma. Saudi Med J. 2018;39(5):514-8.

2. Baltinas J, Weaver T, McCluskey P, Zagora S. Infective conjunctivitis progressing to posterior scleritis. Clin Exp Ophthalmol. 2019;47(6):795-6.

3. Agarwal AM, Dutta MP. Tubercular posterior scleritis: a case report and review of literature. Indian J Ophthalmol. 2019;67(8):1362-5.

4. Alvarez ER, Corless B, Kontzias A, Cebulla CM. Cryopyrin-associated periodic syndrome presenting with posterior scleritis. Rheumatology (Oxford). 2019; 58(12):2337-9.

5. Gonzalez-Gonzalez LA, Molina-Prat N, Doctor P, Tauber J, de la Sainz MM, Foster CS. Clinical features and presentation of posterior scleritis: a report of 31 cases. Ocul Immunol Inflamm. 2014;22(3):203-7.

6. Yang P, Ye Z, Tang J, Du L, Zhou Q, Qi J, et al. Clinical features and complications of Scleritis in Chinese patients. Ocul Immunol Inflamm. 2018; 26(3):387-96.

7. Akpek EK, Thorne JE, Qazi FA, Do DV, Jabs DA. Evaluation of patients with scleritis for systemic disease. Ophthalmology. 2004;111(3):501-6.

8. Sohn EH, Wang R, Read R, Roufas A, Teo L, Moorthy R, et al. Long-term, multicenter evaluation of subconjunctival injection of triamcinolone for non-necrotizing, noninfectious anterior scleritis. Ophthalmology. 2011; 118(10):1932-7.

9. Meintjes G, Scriven J, Marais S. Management of the immune reconstitution inflammatory syndrome. Curr HIV/AIDS Rep. 2012;9(3):238-50. 
10. Urban B, Bakunowicz-Lazarczyk A, Michalczuk M. Immune recovery uveitis: pathogenesis, clinical symptoms, and treatment. Mediat Inflamm. 2014;2014: 971417.

11. Sherif M, Leon L, Clerc O, Guex-Crosier Y. Severe idiopathic posterior Scleritis in a patient with HIV. Klin Monatsbl Augenheilkd. 2017;234(4):571-4.

12. French MA, Price P. Immune restoration disease in HIV-infected patients after antiretroviral therapy. Clin Infect Dis. 2001;32(2):325-6.

13. French MA. HIV/AIDS: immune reconstitution inflammatory syndrome: a reappraisal. Clin Infect Dis. 2009;48(1):101-7.

\section{Publisher's Note}

Springer Nature remains neutral with regard to jurisdictional claims in published maps and institutional affiliations.

Ready to submit your research? Choose BMC and benefit from:

- fast, convenient online submission

- thorough peer review by experienced researchers in your field

- rapid publication on acceptance

- support for research data, including large and complex data types

- gold Open Access which fosters wider collaboration and increased citations

- maximum visibility for your research: over $100 \mathrm{M}$ website views per year

At $\mathrm{BMC}$, research is always in progress.

Learn more biomedcentral.com/submissions 